\title{
Present-day tools for assessing publishing integrity in biomedical science represent valuable work in progress
}

\author{
Durga Prasanna Misra $^{1}$ (1) $\cdot$ Vikas Agarwal $^{1}$ (B) \\ Received: 14 March 2021 / Revised: 14 March 2021 / Accepted: 15 March 2021 / Published online: 25 March 2021 \\ (C) International League of Associations for Rheumatology (ILAR) 2021
}

Dear Editor,

We read with great interest the letter by da Silva [1] written in response to our recent article [2], highlighting lacunae in presently available tools assessing integrity in scientific publishing [1]. The letter brings to attention points related to limitations of ORCID, Publons, declaration of conflicts of interests, and guidelines for ethical scientific publishing provided by organizations such as the International Committee of Medical Journal Editors (ICMJE) and the Committee on Publication Ethics (COPE) [1]. While we agree that these tools and guidelines are not flawless, they represent valuable progress, as we subsequently discuss.

The advent of ORCID has numerous advantages, as discussed in our article, including disambiguation of author identities and the potential to verify authors and their areas of research. Numerous other approaches have also attempted to enable author identity disambiguation, including ResearcherID on the Web of Science database and the Scopus author ID [3, 4]. How ORCID differs from these is its availability free of cost, as opposed to the requirement for subscriptions, mostly at an institutional level, to access Scopus and Web of Science. Some of the limitations of ORCID discussed by da Silva [1] can be overcome by making all the information linked to ORCID identifiers publicly available, instead of relying on the individual manning the identifier account to make this information open.

da Silva has also discussed how Publons might not differentiate high-quality peer review reports from others [1], since many such peer review reports are inaccessible due to journal or author

Durga Prasanna Misra

durgapmisra@gmail.com; dpmisra@sgpgi.ac.in

Vikas Agarwal

vikasagr@yahoo.com; vikasagr@sgpgi.ac.in

1 Department of Clinical Immunology and Rheumatology, Sanjay Gandhi Postgraduate Institute of Medical Sciences (SGPGIMS), Lucknow 226014, India preferences. Publons also cannot presently differentiate reviews for genuine journals from predatory ones. It must be kept in mind that Publons fulfilled the lacuna of a mechanism to collate peer review achievements or record peer reviews on a publicly available platform [2]. Open peer review has been adopted by many journals and, however, has its own limitations. It is not unusual for authors receiving rejections to be critical of the peer review comments simply because they might consider them to be not befitting their status in the scientific community [5]. In our experience as editors, a significant proportion of peer reviewers are early career researchers. If open peer review was universal, early career scientists might be hesitant to critically review papers from senior researchers from their own field, for fear of retribution [6].

Predatory journals have been a scourge of scientific publishing over the past decade [7, 8]. However, consensus attempts to devise definitions for predatory journals by surveying the opinions of international experts in the field have not met with success $[9,10]$. Therefore, it is not surprising that Publons is unable to flag reviews for predatory journals. The ICMJE guidelines do mention about predatory journals and warn authors to avoid such journals [11]. Similar advice is also provided by COPE [12]. However, considering the complexity of the nature of predatory journals, it is unlikely that providing a clear-cut definition or cut-off for defining predatory journals [1] shall be feasible in the near future.

Our article does mention about potential editorial conflicts of interest [2]; these are discussed in greater detail in another article from our group [13]. We concur with da Silva [1] that editorial conflicts of interest require transparent declaration and also agree that editors should avoid dealing with papers from collaborating authors. However, it is also important to realize the honorary nature of editorship in many journals; hence finding a handling editor with absolutely no conflicts of interest might not always be feasible. Transparent declaration of editorial conflicts of interest might be a reasonable middle path towards enabling greater trust in the integrity of editors. 
The article by da Silva [1] has also mentioned the lack of guidelines regarding sting operations in scientific publishing. Sting operations like the Bohannon sting [14] have helped the scientific community understand better the nature of predatory publishing. However, we agree that efforts to clearly delineate the ethical aspects of such sting operations are needed, akin to the overview of any biomedical research involving human subjects by research ethics committees. The pandemic of coronavirus disease 19 has also brought into attention numerous problems related to the integrity of scientific publishing, particularly the reliability of rapid peer reviews balancing the need to rapidly publish information to enable saving of lives during the pandemic [15-17]. International bodies like the ICMJE, COPE, and World Association of Medical Editors might consider these as priority points on their agenda to further improve the present climate of scientific publishing.

\section{Declarations}

Ethical approval This article does not contain any studies with human participants or animals performed by any of the authors.

Conflict of interest Durga Prasanna Misra declares that he has no conflict of interest, including no relationship with pharmaceutical companies.

Vikas Agarwal declares that he has no conflict of interest, including no relationship with pharmaceutical companies.

\section{References}

1. Silva JAT (2021) A reality check on publishing integrity tools in biomedical science. Clin Rheumatol

2. Misra DP, Agarwal V (2020) Integrity of clinical research conduct, reporting, publishing, and post-publication promotion in rheumatology. Clin Rheumatol 39:1049-1060. https://doi.org/10.1007/ s10067-020-04965-0

3. https://guides.lib.uchicago.edu/c.php?g=298332\&p=1989825. Accessed on 14 March 2021

4. Santhanam S (2020) Introducing open researcher and contributor identifier and publons: The digital transformation. Indian $\mathrm{J}$ Rheumatol 15:255-257. https://doi.org/10.4103/injr.injr_191_20

5. Misra DP, Ravindran V (2020) Revisions, rejections and rebuttals: the show must go on! J R Coll Physicians Edinb 50:362-364. https://doi.org/10.4997/jrcpe.2020.403

6. Benos DJ, Bashari E, Chaves JM, Gaggar A, Kapoor N, LaFrance M, Mans R, Mayhew D, McGowan S, Polter A, Qadri Y, Sarfare S,
Schultz K, Splittgerber R, Stephenson J, Tower C, Walton RG, Zotov A (2007) The ups and downs of peer review. Adv Physiol Educ 31:145-152. https://doi.org/10.1152/advan.00104.2006

7. Misra DP, Ravindran V (2020) Current perspectives on predatory or low-quality journals. J R Coll Physicians Edinb 50:224-225. https://doi.org/10.4997/jrcpe.2020.303

8. Misra DP, Ravindran V, Wakhlu A, Sharma A, Agarwal V, Negi VS (2017) Publishing in black and white: the relevance of listing of scientific journals. Rheumatol Int 37:1773-1778. https://doi.org/10. 1007/s00296-017-3830-2

9. Grudniewicz A, Moher D, Cobey KD, Bryson GL, Cukier S, Allen K, Ardern C, Balcom L, Barros T, Berger M, Ciro JB, Cugusi L, Donaldson MR, Egger M, Graham ID, Hodgkinson M, Khan KM, Mabizela M, Manca A, Milzow K, Mouton J, Muchenje M, Olijhoek T, Ommaya A, Patwardhan B, Poff D, Proulx L, Rodger M, Severin A, Strinzel M, Sylos-Labini M, Tamblyn R, van Niekerk M, Wicherts JM, Lalu MM (2019) Predatory journals: no definition, no defence. Nature 576:210-212. https://doi.org/10. 1038/d41586-019-03759-y

10. Cukier S, Lalu M, Bryson GL, Cobey KD, Grudniewicz A, Moher D (2020) Defining predatory journals and responding to the threat they pose: a modified Delphi consensus process. BMJ Open 10: e035561. https://doi.org/10.1136/bmjopen-2019-035561

11. International Committee of Medical Journal Editors (ICMJE) guidelines 2019. http://www.icmje.org/icmje-recommendations. pdf. Accessed on 14 March 2021

12. Committee of Publication Ethics guidance on predatory journals. https://publicationethics.org/files/cope_dd_a4_pred_publishing _ nov19_screenaw.pdf. Accessed on 14 March 2021

13. Misra DP, Ravindran V (2019) Conflicts of interest in academic publishing: when in doubt, declare! J R Coll Physicians Edinb 49: 179-181. https://doi.org/10.4997/jrcpe.2019.301

14. Bohannon J (2013) Who's afraid of peer review. Science 342:60 65. https://doi.org/10.1126/science.342.6154.60

15. Gupta L, Gasparyan AY, Misra DP, Agarwal V, Zimba O, Yessirkepov M (2020) Information and Misinformation on COVID-19: a Cross-Sectional Survey Study. J Korean Med Sci 35:e256. https://doi.org/10.3346/jkms.2020.35.e256

16. Gupta L, Gasparyan AY, Zimba O, Misra DP (2020) Scholarly publishing and journal targeting in the time of the Coronavirus Disease 2019 (COVID-19) pandemic: a cross-sectional survey of rheumatologists and other specialists. Rheumatol Int 40:20232030. https://doi.org/10.1007/s00296-020-04718-x

17. Misra D, Agarwal V (2020) Blaming the peer reviewer: Don't shoot the messenger!! Indian J Rheumatol 15:162-164. https://doi.org/ 10.4103/injr.injr 18720

Publisher's note Springer Nature remains neutral with regard to jurisdictional claims in published maps and institutional affiliations. 